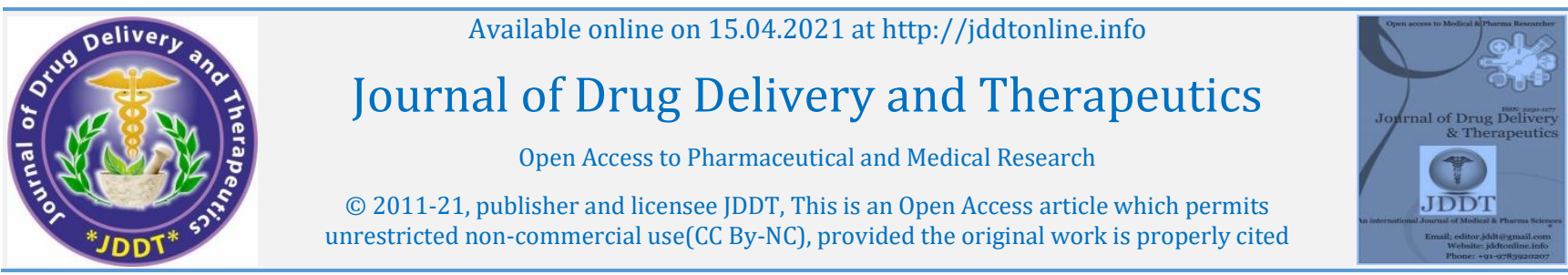
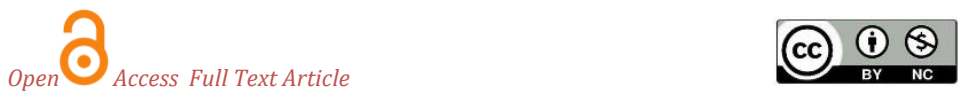

Research Paper

\title{
Antibacterial Activity of Haematococcus pluvialis Crude Astaxanthin Extract
}

\author{
*Ashaq Hussain Rather, Surendra Singh, Sameer Choudhary \\ Algal Biotechnology Laboratory, Department of Post Graduate Studies and Research in Biological Sciences, Rani Durgavati University, Jabalpur- \\ 482001, (M.P.), India
}

Article Info:

Article History:
Received 17 Dec 2020
Review Completed 29 Jan 2021
Accepted 12 Feb 2021
Available online 15 April 2021

Cite this article as:

Rather AH, Singh S, Choudhary S, Antibacterial Activity of Haematococcus pluvialis Crude Astaxanthin Extract, Journal of Drug Delivery and Therapeutics. 2021; 11(2-s):28-30 DOI: http://dx.doi.org/10.22270/jddt.v11i2-s.4662

\section{Abstract}

\begin{abstract}
H. pluvialis is the potential source of natural astaxanthin, which is considered as super antioxidant. In the present investigation, astaxanthin was extracted from the encysted cells of H. pluvialis with acetone, methanol, DMSO and hexane, the crude extracts were tested for four strain (Escherichia coli, Salmonella typhi, Vibrio cholera and Staphylococcus aureus) of bacteria for the antibacterial activity. Highest antibacterial activity was observed as $10.2 \pm 0.20 \mathrm{~mm}$ extracted with acetone on Escherichia coli while as least antibacterial activity was found as $6.1 \pm 0.0 \mathrm{~mm}$ extracted with hexane on Vibrio cholera.
\end{abstract}

Keywords: Haematoccoccus pluvialis; Astaxanthin; Antibacterial.

*Address for Correspondence:

Ashaq Hussain Rather, Algal Biotechnology Laboratory, Department of Post Graduate Studies and Research in Biological Sciences, Rani Durgavati University, Jabalpur-482001, (M.P.), India

\section{INTRODUCTION}

The growing demand in the cosmetic formulation with natural ingredients continues to raise and now-a-days this has been a trend to replace the synthetic preservatives with natural ones. The natural preservatives are preferred from plants, bacteria, fungi, and algal sources. Astaxanthin is a xanthophyll carotenoid ${ }^{1}$. The main biological sources of astaxanthin include crustacean crustacean extracts, Haematococcus pluvialis, yeast Rhodotorularubra, and Phaffia rhodozyma. The aforementioned natural sources cannot compete with the synthetic products available 2. Haematococcus pluvialis, freshwater green microalga is considered a potent producer of pigment astaxanthin ${ }^{3}$. In our previous study 4, $5 \mathrm{H}$. pluvialis was cultivated and astaxanthin was extracted from the green alga $H$. pluvialis. In present study, efforts have been made to study antibacterial activity of Haematococcus pluvialis crude astaxanthin extract.

\section{MATERIALS AND METHODS}

\subsection{Cultivation}

Haematococcus pluvialis culture was obtained from culture collection of algae at the University of Texas, Austin, USA. $H$. pluvialis culture was grown in the bold basal medium (BBM) 6 . The astaxanthin accumulated cells, were harvested, dried in the oven at $70{ }^{\circ} \mathrm{C} 7$.

\subsection{Preparation of Samples}

$10 \mathrm{mg}$ biomass of $H$. pluvialis was mixed in mortar and pestleand extracted with acetone, methanol, DMSO and hexane, centrifuged at $2800 \mathrm{x}$ g for $10 \mathrm{~min}$ at $4{ }^{\circ} \mathrm{C}$, the pellet was discarded and the supernatant was taken for the estimation of astaxanthin. The absorbances of the extracts were determined at $492 \mathrm{~nm}$ and the amount of the pigment was quantitatively measured according to Davies ${ }^{8}$. Acetone was evaporated in the rotary evaporator. The crude astaxanthin extracts were individually tested for Escherichia coli, Salmonella typhi, Vibrio cholera and Staphylococcus aureus. The antibacterial activity was tested using disc diffusion method. $1 \mathrm{ml}$ of test organism at concentration of $10^{-5}$ cells $\mathrm{mL}^{-1}$ was spread on Mueller-Hinton agar plate. 10 $\mu \mathrm{l}$ astaxanthin, extracted with acetone, methanol, DMSO and hexane was poured in the wells. The plates of bacterial strain were incubated at $37{ }^{\circ} \mathrm{C}$ for 24 . The inhibition zone discs were observed and the diameters of clear zones were measured. The bacteria strains were sub cultured and maintained on nutrient agar (Beef extract 3.0 g, Peptone 5.0 g, NaCl 5.0 g, Agar 15.0 g, pH 7.4, dissolved in one liter distilled water and sterilized at $121^{\circ} \mathrm{C}$ for 15 minutes).

\section{RESULTS AND DISCUSSION}

\subsection{Cultivation}

Haematococcus pluvialis was grown in the bold basal medium for 30 days and the cells were harvested and astaxanthin was extracted with different solvents (Figure 1) 


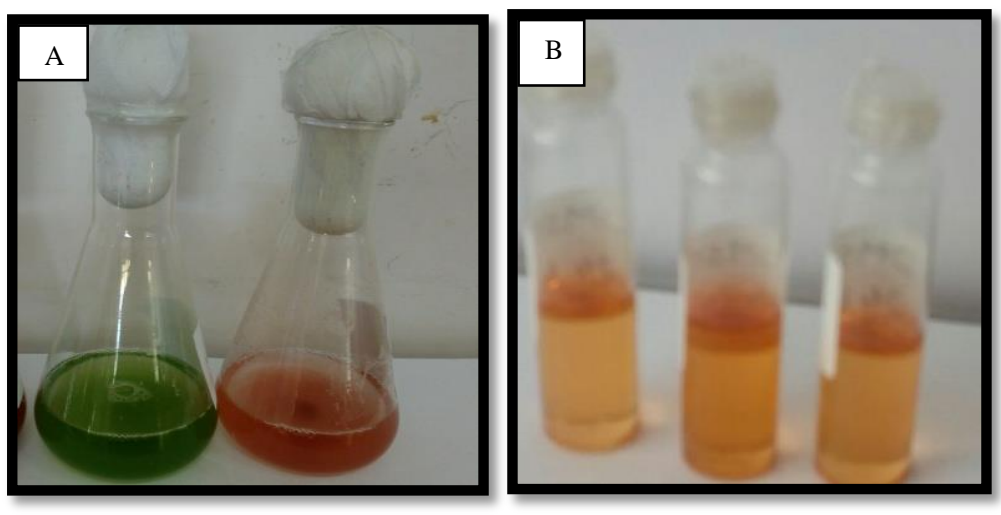

Figure 1: Haematococcus pluvialis (A) green stage and red stage (B) astaxanthin extract

Astaxanthin has been extracted with acetone, methanol, DMSO and hexane and the crude astaxanthin was tested for the E.coli, Salmonella typhi, Vibrio cholera, Staphylococcus aureus. The results showed that the green algae H. pluvialis crude extract $(10 \mu \mathrm{l})$ possess antibacterial activity by showing the inhibition zone around the discs. Highest antibacterial activity was found as $10.2 \pm 0.20 \mathrm{~mm}$ extracted with acetone on Escherichia coli. In methanol, DMSO and hexane extracts, highest antibacterial activity was found as $8.8 \pm 0.12,9.4 \pm 0.15$ and $8.7 \pm 0.12 \mathrm{~mm}$ on Salmonella typhi, Salmonella typhi, Staphylococcus aureus respectively as seen in Table 1.

Table 1: Antibacterial activity of crude $H$. pluvialis astaxanthin

\begin{tabular}{|l|l|l|l|l|}
\cline { 2 - 5 } \multicolumn{1}{c|}{} & \multicolumn{4}{l}{ Inhibition zones of crude astaxanthin (mm) in different bacteria } \\
\hline Solvents & E.coli & Salmonella typhi & Vibrio cholera & S. aureus \\
\hline Acetone & $10.2 \pm 0.20$ & $9.8 \pm 0.15$ & $10.1 \pm 0.15$ & $9.1 \pm 0.12$ \\
\hline Methanol & $8.8 \pm 0.12$ & $7.5 \pm 0.12$ & $7.4 \pm 0.12$ & $6.1 \pm 0.10$ \\
\hline DMSO & $8.2 \pm 0.15$ & $9.4 \pm 0.15$ & $7.3 \pm 0.20$ & $7.6 \pm 0.20$ \\
\hline Hexane & $6.6 \pm 0.10$ & $7.2 \pm 0.20$ & $6.1 \pm 0.10$ & $8.7 \pm 0.12$ \\
\hline
\end{tabular}

The antioxidant activities of astaxanthin are better than $\beta$ carotene and vitamin-E. This is the reason due to which makes it protects against inflammation, UV radiation, aging and skin cancer. Astaxanthin is used in cosmetic, food and feed industries. H. pluvialis astaxanthin is found effective agent for the regulation and maintenance of uric and hepatic enzymes in rat model animals ${ }^{9}$. The pharmacokinetic data has revealed that a single dose of $10 \mathrm{mg}$ astaxanthin can remain in the human blood for a day and $100 \mathrm{mg}$ for approximately three days ${ }^{10}$. A dose of $1 \mathrm{mg}$ when given once daily for a month can increase the blood levels ${ }^{11}$. The animal study showed that astaxanthin higher than $120 \mathrm{mg}$ a day in human 12 , revealed no harmful effects. Gonzalez et. al 13 observed that extract of green algae have umpteen antimicrobial activities against $B$. subtilis and $S$. aureus. The green algae extract showed potential effects against Grampositive bacteria ${ }^{14}$.

\section{CONCLUSION}

The current results revealed that crude astaxanthin extracts prevented the bacterial activity hence $H$. pluvialis astaxanthin may be consider as a preservative in different food formulations.

\section{ACKNOWLEDGEMENT}

We are thankful to the head, department of post graduate studies and research in biological sciences, Rani Durgavati University, Jabalpur-482001, (M.P.) India for providing necessary facilities.

\section{CONFLICT OF INTEREST}

We declare that we have no conflict of interest.

\section{REFERENCES}

1. Higuera-Ciapara I, Felix-Valenzuela L, Goycoolea F M, Astaxanthin: A review of its chemistry and applications. Criti. Reviews in Food Sci. and Nutri. 2006; 46:185-196.

2. Johnson E A, An G H, Astaxanthin from Microbial Sources. Crit. Reviews in Biotechnol. 1991; 4:297-326.

3. Kobayashi M, Kakizono T, Nagai S, Astaxanthin production by a green algal, Haematococcuspluvialis accompanied with morphological changes in acetate media. J. Ferment. Bioengng. 1991; 71(5):335-339.

4. Rather A H, Singh S, Preliminary evaluation of impact of monochromatic light on the biosynthesis of astaxanthin in green alga Haematococcus pluvialis.World News of Nat. Sci. 2018; 19:45-50.

5. Singh S, Rather A H, Impact of light and dark (L/D) period on the biosynthesis of astaxanthin in green alga Haematococcus pluvialis J. App. Biol. Biotech. 2018; 6(06):58-60.

6. Kanz T, Bold H C, Physiological Studies nine morphological and taxonomic investigations of Nostoc and Anabaena in Culture, Austin Texas, University of Texas, publ. 1969; pp 6924.

7. Sarada R, Vidhyavathi R, Usha D, Ravishankar G A, An efficient method for extraction of astaxanthin from green alga Haematococcuspluvialis. J. of Agri. and Food Chem. 2006; 4:7585-7588.

8. Davies B H, Carotenoids Chemistry and biochemistry of plant pigments, W. Ed, Academic Press, London 1976; 38-166.

9. Ashaq H R, Rekha R, Effect of Haematococcus pluvialis crude astaxanthin extract on uric acid and hepatic enzymes. Drug Invent. Today 2020; 14 (2):366-369. 
10. Coral-Hinostroza G N, Ytrestoyl T, Ruyter Band Bjerkeng B, Plasma appearance of unesterified astaxantin geometrical E/Z and optical R/S isomers in men given single doses of a mixture of optical 3 and 3'R/S isomers of astaxanthin fatty acyl diesters. Comp. Biochem. Physiol. Toxicol. Pharmacol. 2004; 139:99-110.

11. Miyazawa T, Nakagawa K, Kimura F. Plasma, carotenoid concentrations before and after supplementation with astaxanthin in middle-aged and senior subjects. Biosci. Biotechnol. Biochem. 2011; 75:1856-1858.
12. Reagan-Shaw S, Nihal M, Ahmad N, Dose translation from animal to human studies revisited. FASEB J. 2008; 22:659-661.

13. Gonzalez-del-Val A, Platas A, Basilio A, Screening of antimicrobial activities in red, green and brown macroalgae from Gran Canaria. Int. Microbio. 2001; 4:35-40.

14. Afifah S N, Darah I, Fariza S S, Nordin M M J, Aili Z N, Antimicrobial activity of various extracts of a tropical chlorophyta macroalgae, Halimeda discoidea, J. of Appl. Sci. 2010; 10(23):3007-3013. 